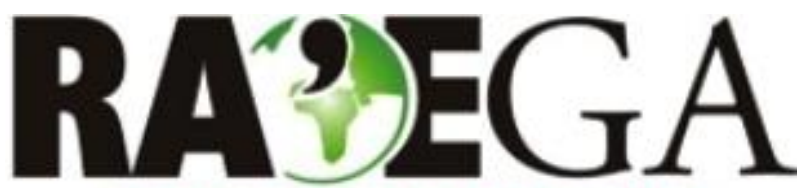

O ESPACCO GEOGRÁFICO EM ANÁLISE

\title{
ANÁLISE DO PREÇO DE TERRAS AGRÍCOLAS NO TOCANTINS: DECIFRANDO OS CAMINHOS DO AGRONEGÓCIO
}

\section{ANALISYS OF AGRICULTURE LAND PRICES IN TOCANTINS: DECIPHERING THE PATHS OF AGRIBUSINESS}

\author{
Debora Assumpção Lima ${ }^{1}$, Mariana Leal Conceição Nobrega ${ }^{2}$
}

\section{RESUMO}

$\mathrm{O}$ artigo pretende analisar as recentes mudanças o espaço agrário do Tocantins sob a ótica do avanço do agronegócio. A partir da análise do mercado de terras e o conceito de renda diferencial, é possível compreender o comportamento do preço das terras agrícolas e a evolução dos plantios de grãos, em principal a soja. 0 mercado de terras está diretamente atrelado à expansão de infraestruturas para o avanço de monocultivos relevantes para a balança comercial. Além do avanço dos plantios homogêneos, as formas capitalistas, e a acumulação de capital na renda da terra acompanham tal movimento de expansão.

PALAVRAS-CHAVE: mercado de terras, fronteira agrícola, circuito espacial produtivo, soja.

\section{ABSTRACT}

This article aims to analyze the recent changes the agrarian space of Tocantins on the perspective of the expansion of agribusiness through in this state. From the land market analysis and the concept of differential rent, it is possible to understand the price's behavior of agricultural land and the development of grain crops, especially soybeans. The land market is directly linked to the expansion of infrastructure, especially transport, to the advancement of important monocultures for the trade commercial balance. Besides the increase of plantations, the capitalist forms accompany this movement of expansion, in which the forms of capital accumulation are also present in land rent. Thus, agribusiness invades the Tocantins and consolidates as main export activity.

KEY-WORDS: land market, agricultural frontier, spatial productive and economic circuit, soy.

\footnotetext{
${ }^{1}$ Universidade Estadual de Campinas Campinas/SP, e-mail: deborassumpcaolima@gmail.com

${ }^{2}$ Universidade Estadual de Campinas Campinas/SP, e-mail: alemdalogica@yahoo.com.br
} 


\section{ANÁLISE DO PREÇO DE TERRAS AGRÍCOLAS NO TOCANTINS: DECIFRANDO OS CAMINHOS DO AGRONEGÓCIO}

\section{INTRODUÇÃO}

Um sério problema do mundo rural brasileiro é a insegurança da propriedade da terra ${ }^{3}$. Uma das principais características da constituição da propriedade da terra do Brasil é a propriedade de domínio privado que se deu num processo de domínio do patrimônio público ${ }^{4}$.

O mercado de terras conta sua história juntamente com a grilagem, com o avanço do Estado e o modo de produção capitalista. Como já indicava Monbeig (1984), o mercado de terras está atrelado à expansão de infraestruturas, em especial o transporte, para o avanço de monocultivos importantes para a balança comercial. Além do avanço dos plantios homogêneos, as formas capitalistas acompanham tal movimento de expansão, em que as formas de acumulação de capitais também estão presentes na renda da terra. Vale ressaltar que a circulação é fundamental para a realização do capital: "a circulação do capital é ao mesmo tempo seu devir, seu crescimento, seu processo vital" (MARX, 2011, p. 426).

\footnotetext{
3 Concorda-se com Oliveira (2001) que para discutir a expansão da fronteira agrícola e o avanço do monocultivo da soja é necessário refletir sobre as questões relativas à grilagem das terras públicas e devolutas e, a concentração fundiária. De acordo com sua apresentação no último Encuentro de Geógrafos de America Latina (XV EGAL) realizado em Cuba e sua palestra "Reforma Agrária na gestão do PT" proferida na Universidade Estadual de Campinas (UNICAMP) em maio de 2015, a participação do Estado na grilagem, executada pelo Instituto Nacional de Colonização e Reforma Agrária (INCRA) é fundamental para a grilagem de novas terras públicas ao agronegócio, principalmente no Mato Grosso e nos cerrados do Centro-Norte, onde se localiza o Tocantins

4 Interessante registrar que o problema da propriedade da terra remonta o primeiro projeto de lei de terras que data de 1843. Os projetos de colonização promoviam vendas de terras devolutas, proibição das posses e invasões, e limitação das posses. Uma das formas de embargar o projeto e ocultar a apropriação (de grandes áreas que ocorriam corriqueiramente) era apontar os problemas existentes relativos à medição e demarcação de terras. Além disso, o tamanho dos lotes a serem vendidos pelo governo não levava a crer que o objetivo fosse o estabelecimento da pequena propriedade. Para um estudo mais aprofundando sobre os projetos de lei de terras no Brasil, ver SILVA, 2008, em principal p.105-124 e p.275-303
}

O avanço da soja do Tocantins não foge à regra: projetos agrícolas ${ }^{5} \mathrm{e}$ incentivos governamentais, expansão de ferrovias e rodovias são fundamenteis para a expansão do agronegócio ${ }^{6}$ no estado (LIMA, 2014), importante não só para o crescimento das áreas cultivadas, mas também como possível rota de escoamento da produção dos cerrados do Centro-Norte. Neste sentido, a fluidez do território é

\footnotetext{
5 Sobre os projetos agrícolas tecnificados no Tocantins podese destacar: 1.Projeto Javaés: implantado na região sudeste do Tocantins, envolve os municípios de Formoso do Araguaia, Dueré e Lagoa da Confusão. Esta forma de avanço de fronteira está incorporada a lavoura tecnificada com plantação de arroz através do sistema de irrigação por inundação. As culturas de milho, soja, feijão, girassol, também são cultivadas no sistema de subirrigação. Abrange uma área total de 1 milhão de ha. Com diversos percalços, é o atual Prodoeste. 2.Prodecer III: programa de cooperação com o Japão, implementado em Pedro Afonso. O plano investiu na produção de soja, milho e sorgo, sendo que o projeto se firmou na produção dos dois primeiros; o empreendimento foi feito de forma integrada, englobando as fases de produção, comercialização e industrialização em uma área de 40.000 ha. 3.Região Nordeste: no município de Campos Lindos vem sendo desenvolvida uma produção de grãos voltada para soja, arroz e milho, estimulada pelo Projeto Agrícola de Campos Lindos; além do cultivo de frutas tropicais. Essa área está sendo preparada para tornar-se um polo de alto padrão tecnológico. 4.Região Sudeste: a pecuária é significativa e tem recebido incentivos do governo. È o eixo de desenvolvimento da região, associada a melhoria do uso de tecnologia para agricultura no Projeto Manuel Alves no município de Dianópolis.5.PDRI: Programa de Desenvolvimento Rural Integrado. Localizado no extremo norte na região do Bico do Papagaio, tem como objetivo aproveitar as potencialidades locais, sendo o subprojeto Sampaio área piloto deste programa. Abrange 19.500ha de cerrado, dos quais 10.080 ha destinados ao cultivo de arroz, soja, milho e feijão.

6 Entende-se que a definição de agronegócio aqui retratada está fortemente ligada à agricultura de precisão, ou agricultura científica, uma vez que "a agricultura de precisão está associada a estratégias de gestão que utilizam a tecnologia da informação para o recolhimento e análise de dados a fim de apoiar decisões relacionadas à agricultura. Estes sistemas informatizados também se destinam a aumentar a eficácia e a eficiência da produção em uma área específica ou em toda a propriedade, além de buscar maiores ganhos com minimização simultânea dos custos de produção e impactos ambientais por atividades agrícolas e pecuárias, embora o sistema por si só não implica necessariamente uma produção ambientalmente amigável (LOCATEL e CHAPARRO, $2004, s / p)$
} 
fundamental para conectar as áreas do agronegócio tocantinense aos mercados globais, podendo ser definida como

[...]aquela qualidade dos territórios nacionais que permite uma aceleração cada vez maior dos fluxos que o estruturam, a partir da existência de uma base material formada por um conjunto de objetos concebidos, construídos e/ou acondicionados para garantir a realização do movimento. Esses fixos produtivos servem nos diferentes momentos do processo produtivo: na produção propriamente dita (stricto sensu), na distribuição, na troca, no consumo (Arroyo, 2001, p.105).

O modo de produção capitalista procura assegurar a fluidez dos elementos que utiliza, manipula e combina (RAFFESTIN, 2011). No que tange ao escoamento de commodities produzidas no Tocantins pode-se destacar uma complexa rede intermodal e quatro grandes complexos portuários: Suape (PE), Pecém (CE), Aratu/llhéus (BA), Itaqui/Ponta Madeira (MA) e Vila do Conde/Belém (PA). A Estrada de Ferro Carajás e a Ferrovia Norte-Sul centralizam o corredor de escoamento de exportação por diversas rodovias, como a BR-230 e a BR-010, que junto com a TO040 conectam o Tocantins aos cerrados piauienses e maranhenses e baianos. A rodovia BR-235 corta o centro-norte do estado, sobrepondo-se a TO-336 no entroncamento com a rodovia Belém-Brasília, próximo ao município Pedro Afonso. A Transmazônica, BR-230, corta o Bico do Papagaio, entre os municípios de Araguatins em direção a Aguiarnópolis, onde encontra um pátio da ferrovia Norte-Sul. São corredores que fazem parte dos macrossistemas técnicos de uso predominantemente corporativo, em que a funcionalização do espaço tem um propósito mercantil, favorecendo as ações das empresas do agronegócio - tradings e agroindústrias. 


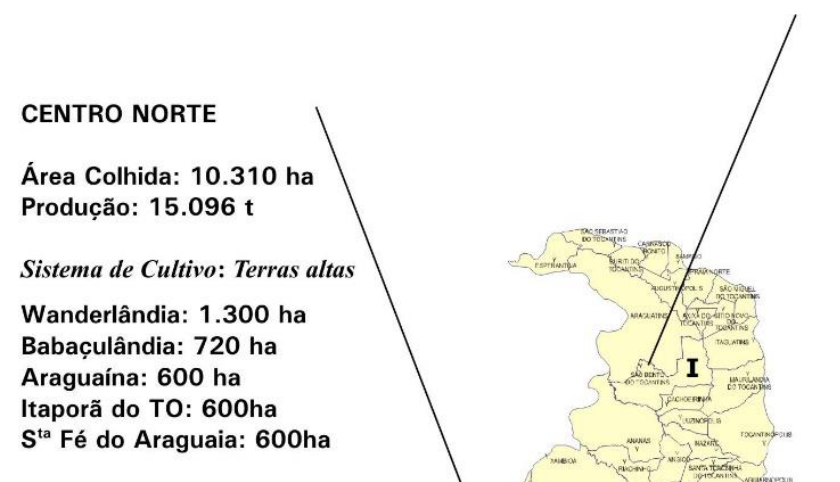

CENTRO OESTE Área Colhida: 21.560 ha
Produção: 3.834 t

Sistema de Cultivo: Terras altas

Marianópolis: 3.800 ha Brejinho de Nazaré: 3.200 ha

Pium: 2.560 ha

Caseara: 1.150 ha

Araguacema: 1.000 ha

Nova Rosalândia: 940 ha

Divinópolis: 800 ha

Colméia: $\mathbf{8 0 0}$ ha

Chapada de Areia: 800 ha

Dois Irmãos: 780 ha

Sistema de Cultivo: Irrigado

Pium: 650 ha

\section{SUDOESTE}

Área Colhida: 66.745 ha Produção: 261.004 t

Sistema de Cultivo: Terras altas

Formoso do Araguaia: $400 \mathrm{ha}$ Lagoa da Confusão: 1.500 ha

Dueré: 1.000 ha

Cristalândia: 1.000ha

Santa Rita do TO: 1.800 ha

Figueirópolis: 1.800 ha

Gurupi: 900 ha

Sistema de Cultivo: Irrigado

Formoso do Araguaia: 23.540 ha

Lagoa da Confusão: 23.000 ha

Dueré: 6.400 ha

Cristalândia: 900 ha

\section{EXTREMO NORTE}

Área Colhida: 15.590 ha

Produção: $21.462 \mathrm{t}$

Sistema de Cultivo: Terras altas

Darcinópolis: 3.270 ha

Araguatins: 1.750 ha

Palmeiras do TO: 1.400 ha

Angico: 1.100 ha

Ananás: 800 ha

São Bento: 600 ha

\section{NORDESTE}

Área Colhida: 14.800 ha

Produção: 27.867 t

Sistema de Cultivo: Terras altas

Campos Lindos: 6.800 ha

Goiatins: 2.450 ha

Barra do Ouro: 1.500 ha

Pedro Afonso: 1.000 ha

LESTE

Área Colhida: 14.770 ha

Produção: 27.664 t

Sistema de Cultivo: Terras altas

Porto Nacional: 4.800 ha Monte do Carmo: 1.900 ha Ponte Alta do TO: 2.200 ha Palmas: 1.580 ha Mateiros: 1.150 ha Aparecida do Rio Negro: 700 ha

Palmas: 1.580 ha

Sistema de Cultivo: Irrigado

Porto Nacional: 190 ha SUDESTE

Área Colhida: 18.360 ha Produção: 30.148 t

Sistema de Cultivo: Terras altas

Santa Rosa do TO: 2.000 ha

Silvanópolis: $\mathbf{3 . 3 0 0}$ ha

Peixe: 2.000 ha

Pindorama: 1.930 ha

Almas: 1.010 ha

Paranã: 900 ha

Taguatinga: 750 ha

Natividade: 750 ha

Ipueiras: 700 ha

Mapa 1.1 - Sistemas de cultivos científicos no Tocantins (2008) Fonte: Secretaria de Agricultura, da Pecuária e do Desenvolvimento Agrário.

\section{MATERIAIS E MÉTODOS}

\subsection{TOCANTINS E A FRONTEIRA AGRÍCOLA} MODERNA
A fronteira agrícola (re)produz um espaço geográfico através de incorporação de terras sob a lógica dos sujeitos hegemônicos do 


\section{ANÁLISE DO PREÇO DE TERRAS AGRÍCOLAS NO TOCANTINS: DECIFRANDO OS CAMINHOS DO AGRONEGÓCIO}

processo de reprodução do capital frente aos espaços marginalizados.

As diversas frações do espaço estão ao alcance dos diversos capitais segundo hierarquizações e lógicas diversas na busca da eficácia do lucro com o auxílio das tecnologias e do trabalho. Quanto maior a diferença entre os tempos de produção e de trabalho, menor é a taxa de lucro da atividade, acentuando a necessidade da simultaneidade entre a ordem (global) e a ação em espaços distantes (local). Apesar do avanço da lógica capitalista, diferentemente da homogeneização dos territórios proposta por Francisco de Oliveira ${ }^{7}$ (1977), há uma especialização e diferenciação dos espaços. Os territórios redefinem as técnicas e vice-versa: cada objeto e evento que se espacializa em seu tecido preexistente integrando-se à vida, ganha uma significação relativa, uma especificidade e, apesar da especificidade de cada território, o espaço encontra-se suscetível a monopolização do território.

O território, assim como o espaço geográfico, parte da noção de "um conceito político e geográfico, porque o espaço geográfico é tanto compartimentado quanto organizado através de processos políticos". Esses processos políticos são responsáveis por regular a circulação do espaço, tornando-se fundamental para a compreensão do uso de território e a circulação de bens e pessoas no espaço (GOTTMAN, 2012, p. 526). Desse modo, o território e seu uso permitem captar os movimentos que ocorrem no espaço, a relação entre os fluxos - características do prisma de análise dos circuitos espaciais produtivos

\footnotetext{
7 Pode-se relativizar a afirmativa quando o próprio autor também aponta que essa tentativa de homogeneização do espaço é sempre pretendida pelas forças do capital, mas nunca totalmente alcançada. Até porque há a necessidade inerente ao capitalismo de sempre haver criação de lucro, como aponta Harvey (2011), pois é "muito claro que a reprodução do capitalismo implica a realização de novas geografias, por meio da destruição criativa do velho, é uma boa forma de lidar com o problema permanente da absorção do excedente de capital" (p.174).
}

(SANTOS; SILVEIRA, 2001). A compreensão do circuito espacial produtivo de grãos no Tocantins auxilia a entender o uso do território através da dinâmica de fixos e fluxos, além de permitir identificar a situação dos lugares em relação à divisão territorial do trabalho.

Não perdendo de vista os movimentos da fronteira, a fronteira agrícola moderna pode ser definida como a ocupação de áreas por atividades agrícolas com alto conteúdo tecnológico e organizacional à formas tradicionais de cultura, particularmente a pequena produção familiar de origem ancestral ou de frentes de ocupação (CASTILLO e FREDERICO, 2011), já que a acepção de fronteira que se adota é a de "fronteira agrícola moderna", entendendo-a como metonímia deste complexo movimento de avanço capitalista via industrialização da agricultura, relacionada ao avanço da fronteira a partir de monocultivos tecnificados controlados por empresas monopolistas transnacionais que detém o controle do circuito espacial produtivo. Por circuitos espaciais de produção pressupõe-se a circulação de fluxos materiais e imateriais no encadeamento das instâncias geograficamente separadas da produção, distribuição, comercialização e consumo num movimento permanente.

A expansão dos circuitos espaciais produtivos torna mais complexa a gestão e o ordenamento dos fluxos materiais e imateriais, fazendo das grandes corporações os agentes privilegiados da articulação entre os lugares, ou seja, da unificação das diversas etapas, geograficamente segmentadas da produção" (CASTILLO e FREDERICO, 2011, p.462).

Pensando o espaço tocantinense como sertão, como hinterlândia e fundo territorial, o agronegócio encara os fundos territoriais como áreas não devastadas, autênticos estoques de terras e recursos naturais para apropriação futura, um espaço a ser colonizado. Não se pode esquecer que "a violência e a expropriação são 


\section{ANÁLISE DO PREÇO DE TERRAS AGRÍCOLAS NO TOCANTINS: DECIFRANDO OS CAMINHOS DO AGRONEGÓCIO}

assim dados irredutíveis desse processo, variando em grau, mas sempre presentes em suas manifestações" (MORAES, 2002, p.144).

O baixo preço da terra é inicialmente atrativo, contudo, a intensificação do valor de troca, ou sua mera especulação, provocam um crescimento geométrico do preço da terra.

Ao examinar as formas de renda fundiária se manifestar, ou seja, o arrendamento que é pago a título de renda fundiária ao proprietário da terra pela utilização do solo, seja para fins produtivos, seja para fins consumptivos, cabe registrar que o preço das coisas que não tem por si nenhum valor, ou seja, que não são produto de trabalho [...] Para vender uma coisa, é preciso apenas que seja monopolizável e alienável (MARX, 1985, p.137).

Para Marx (2011), valor é o substrato (ou essência), que é realizado quando algo é vendido por um determinado preço. Além disso, enquanto o valor (de troca) é a quantidade de trabalho humano incorporada em uma mercadoria. Já o preço toma alguma forma historicamente determinada, como a forma de dinheiro nos tempos atuais, sendo o preço a atualidade (momentânea) do valor.

A primeira categoria em que se apresenta a riqueza burguesa é a da mercadoria, tendo neste texto a terra como tal. Se tomamos aqui a outra premissa de Marx sobre a mercadoria, que para se efetivar como tal e cumprir seu devir, a mercadoria deve circular e ser "vendida" a partir de uma relação de troca, podemos afirmar que a circulação de capital é realizadora de valor, assim como o trabalho-vivo é a criação do valor.

A terra enquanto renda fundiária (HARVEY, 2013) atua como um ativo de reserva de valor, já que permite a conservação da riqueza e também é ferramenta especulativa. Dentre os elementos que determinam o preço da terra, pode-se elencar a localização, infraestrutura de comercialização, impostos, legislação ambiental, contexto socioeconômico e político, inflação e características hidrográficas e edafoclimáticas, determinantes da renda diferencial I da terra; infraestruturas de produção, disponibilidade de mão-de-obra, grau de fragmentação e tamanho da propriedade, fatores que compõem a renda diferencial II (MARX, 1985; OLIVEIRA, 2007). A renda da terra aqui pode estar diretamente ligada a produção ou meramente a seu caráter especulativo e rentista. Desta feita, a valorização capitalista do espaço realiza as determinações gerais do modo de produção capitalista, construindo territórios únicos, onde através do desenvolvimento técnico, se agrega cada vez mais trabalho morto. O que há é a redefinição do valor dos lugares, nos quais a valorização capitalista do espaço é a própria valorização do capital.

\section{RESULTADOS E DISCUSSÃO}

Um fato interessante é a "área para exploração" descrita na tabela 1.1, endossando a teoria de "fundos territoriais" (MORAES, 2002) disseminada pelo Estado. Não é possível determinar com clareza quais seriam estas áreas (a não ser por exclusão do valor total a soma das outras áreas descritas na tabela e, mesmo assim, não seria possível espacializá-las). No entanto, é fundamental para a estratégia de atração do agronegócio um discurso atrelado a um grande estoque de terras para exploração agrícola intensiva. De acordo com a organização dos dados pela SEAGRO - TO (2012), as áreas de pastagens também seriam áreas potenciais para a agricultora moderna) 


\section{ANÁLISE DO PREÇO DE TERRAS AGRÍCOLAS NO TOCANTINS: DECIFRANDO OS CAMINHOS DO AGRONEGÓCIO}

Tabela 1.1 - Disponibilidade e discriminação de terras do Tocantins (2012)

\begin{tabular}{lll}
\hline DISCRIMINAÇÃO DA ÁREA & Hectares & Percentuais (\%) \\
\hline ÁREAS COM RESTRIÇÃO & $\mathbf{1 3 . 9 9 0 . 0 0 0}$ & $\mathbf{5 0 , 2 5}$ \\
\hline Áreas potenciais p/ conservação & 1.266 .690 & $\mathbf{4}, 55$ \\
\hline Parques estaduais & 88.930 & 0,32 \\
\hline Parques nacionais & 562.310 & $\mathbf{2 , 0 2}$ \\
\hline Áreas indígenas & 2.007 .470 & $\mathbf{7 , 2 1}$ \\
\hline Áreas de proteção ambiental & 1.790 .550 & 6,43 \\
\hline Corpos de água & 665.600 & $\mathbf{2 , 3 9}$ \\
\hline Minerações e uso urbano & 30.450 & $\mathbf{0 , 1 1}$ \\
\hline Áreas de reserva legal (nas propriedades) & 6.315 .000 & $\mathbf{2 2 , 6 8}$ \\
\hline Áreas de pres. Permanente (nas propriedades) & 1.263 .000 & $\mathbf{4 , 5 4}$ \\
\hline ÁREA PARA PRODUÇÃo AGRícoLA & $\mathbf{1 3 . 8 5 2 . 0 7 0}$ & $\mathbf{4 9 , 7 5}$ \\
\hline Pastagens (natural e plantada) & 7.498 .250 & $\mathbf{2 6 , 9 3}$ \\
\hline Área agrícola grãos explorada & $\mathbf{8 2 5 . 0 0 0}$ & $\mathbf{2 , 9 6}$ \\
\hline Área para exploração & 5.528 .820 & $\mathbf{1 9 , 8 6}$ \\
\hline ÁREA TOTAL & $\mathbf{2 7 . 8 4 2 . 0 7 0}$ & $\mathbf{1 0 0 , 0 0}$
\end{tabular}

Fonte: Secretaria da Agricultura e Pecuária e Abastecimento do Estado do Tocantins, 2012. Obs: As áreas de reserva legal e de preservação permanente obedecem ao antigo Código Florestal, Lei $\mathrm{n}^{\circ}$ $4771 / 1965$.

As terras na região Norte do país são aquelas de menor preço, e com preço da terra abaixo das outras regiões e investimentos em logística, o avanço da agricultura moderna vem acontecendo de forma abrupta. Vale ressaltar que em 2006 a área de lavouras permanentes e temporárias no estado ocupava 633.265 ha (IBGE, 2012). Atualmente, somente as terras utilizadas para a produção de grãos já ultrapassam a área total destinada para produção agrícola no ano de 2006, se levarmos em conta os números apresentados pela SEAGRO (2012) na tabela 1.1.

O preço de terras no Brasil tem aumentado desde 2000. As terras de pastagem foram as que mais subiram, seguidas das terras de lavouras (FNP, 2000-2014). Neste ano, as terras de matas praticamente não registraram aumento, já que em grande parte são reservas legais de propriedades e são dificilmente utilizáveis para as atividades agropecuárias modernas.
Desde 2002 percebe-se um aumento do volume de vendas de terra com pagamentos em soja, mesmo em regiões não produtoras do grão, onde a oscilação no preço da commoditiy ${ }^{8}$ implica, por conseguinte, em alterações no preço da terra. O milho também aparece nas negociações, mas em menor frequência (FNP, 2002, 2003). A ocupação de áreas para o plantio de soja registraram os maiores aumentos a partir de 2001, acompanhando a tendência de vendas

\footnotetext{
8 Por commoditiy entendemos um produto primário ou semielaborado, mineral ou agrícola, padronizado mundialmente, cujo preço é cotado nos mercados internacionais, em bolsas de mercadorias. Trata-se de uma invenção não apenas econômico-financeira, mas também política, que enfraquece e submete o produtor local - pelo menos quando se trata de commodity agrícola - a uma lógica única ou global e a uma situação sobre a qual não se exerce nenhum controle, favorecendo os compradores ou a grandes empresas de comercialização (tradings). A lógica das commodities opõe agentes atrelados ao lugar ou á região aos agentes que atuam em rede" (CASTILLO, 2011, p.340).
} 


\section{ANÁLISE DO PREÇO DE TERRAS AGRÍCOLAS NO TOCANTINS: DECIFRANDO OS CAMINHOS DO AGRONEGÓCIO}

mediadas pelo produto. Assim como observado em Marx (1985), a renda global da terra cresce pela mera expansão do cultivo ou sua especulação nos mercados futuros, junto ao emprego de capital e trabalho na terra. O avanço da fronteira agrícola moderna no Tocantins significa a escassez relativa da oferta de terras, pressupondo aqui os seus elementos diferenciais apresentados por Ricardo (1988) e Marx (2011, 1985), provocando uma ascensão nos preços das terras. Sua característica como ativo de valor, apontada anteriormente, e rentista aparecem aqui também como outro fator de valorização.

\subsection{O AVANÇO DA AGRICULTURA MODERNA E A TERRA ENQUANTO REPRODUÇÃO DO CAPITAL}

Percebe-se que o avanço das formas capitalistas na região da fronteira agrícola não é um processo único e homogêneo, mas organiza distintas estratégias para sua reprodução. Dentro delas, ele pode efetivamente territorializar-se quando se apropria da terra para a expansão da monocultura agrícola ou quando apenas garante a monopolização do território, mas sem se territorializar, pois se utiliza da terra e do trabalho do camponês para reproduzir-se (OLIVEIRA, 1998). Sobre as transformações no campo, Elias (2006), sem contradizer Oliveira (1998), aponta:

\footnotetext{
a reestruturação da agropecuária brasileira, isto é, a intensificação do capitalismo no campo, com todas as possibilidades advindas da revolução tecnológica,
}

\begin{abstract}
processou-se de forma socialmente excludente e espacialmente seletiva. Diante disso, manteve intocáveis algumas estruturas sociais, territoriais e políticas incompatíveis com os fundamentos do verdadeiro significado do conceito de desenvolvimento. Isso significa que privilegiou determinados segmentos sociais, econômicos e os espaços mais rapidamente suscetíveis de uma reestruturação sustentada pelas inovações científicotécnicas e pela globalização da produção e consumo (ELIAS, 2006, p. 31).
\end{abstract}

Atualmente, vem se instalando um mercado altamente especulativo de terras nos pontos seletivos do território tocantinense, onde os preços ainda são mais baixos se comparados a áreas mais antigas ou consolidadas da fronteira agrícola, como o Oeste da Bahia, em que se observa a presença de especuladores, brasileiros e estrangeiros desde a década de 1980. Foram registrados no Brasil no ano de 2011, $34.371 \mathrm{mil}$ imóveis rurais em nome de estrangeiros, espalhados em uma área de 4.348 milhões de hectares (CASTILHO, 2012). No Tocantins, chineses, em especial, vêm comprando terras no município de Lagoa da Confusão e Formoso do Araguaia (dado recolhido em trabalho de campo em 2012). Em Paraíso do Tocantins, investidores americanos vêm estabelecendo parcerias na compra de terra para plantio de grãos com produtores brasileiros. 
LIMA,D.A. e NOBREGA,M.L.C.

ANÁLISE DO PREÇO DE TERRAS AGRÍCOLAS NO TOCANTINS: DECIFRANDO OS CAMINHOS DO AGRONEGÓCIO

Tabela 1.2 - Valor da terra nua no Tocantins $\left(2007^{9}\right)$

\begin{tabular}{|c|c|c|c|c|c|c|}
\hline \multirow[t]{2}{*}{ Microrregião } & \multicolumn{3}{|c|}{ Valor da terra nua/há } & \multirow{2}{*}{$\begin{array}{l}01 \text { módulo } \\
{ }^{10} \text { fiscal } \\
\text { (valor } \\
\text { mínimo) }\end{array}$} & \multirow{2}{*}{$\begin{array}{l}04 \text { módulos } \\
\text { fiscais (valor } \\
\text { mínimo) }\end{array}$} & \multirow{2}{*}{$\begin{array}{l}15 \text { módulos } \\
\text { fiscais (valor } \\
\text { mínimo) }\end{array}$} \\
\hline & Mínimo & Médio & Máximo & & & \\
\hline $\begin{array}{ll}\text { Bico do } \\
\text { Papagaio }\end{array}$ & 619,43 & $1.136,36$ & $1.652,89$ & $49.554,40$ & $198.217,60$ & $743.316,00$ \\
\hline Araguaína & 206,61 & $1.652,89$ & $3.099,17$ & $16.528,80$ & $66.115,20$ & $247.932,00$ \\
\hline $\begin{array}{l}\text { Miracema do } \\
\text { Tocantins }\end{array}$ & 206,61 & $1.136,26$ & $2.666,12$ & $16.528,80$ & $66.115,20$ & $247.932,00$ \\
\hline Rio Formoso & 361,57 & 645,66 & 929,75 & $28.925,60$ & $115.702,40$ & $433.884,00$ \\
\hline Gurupi & 123,97 & 836,78 & $1.549,59$ & $9.917,60$ & $39.670,40$ & $148.764,00$ \\
\hline Porto Nacional & 258,25 & 748,97 & $1.239,57$ & $20.660,00$ & $82.640,00$ & $309.900,00$ \\
\hline Jalapão & 61,98 & 647,52 & $1.333,08$ & $4.958,40$ & $19.833,60$ & $74.376,00$ \\
\hline Dianópolis & 103,31 & $1.084,71$ & $2.066,12$ & $8.264,80$ & $33.059,20$ & $123.972,00$ \\
\hline Valores médios & 242,72 & 986,14 & $1.817,04$ & $19.417,30$ & $77.669,20$ & $291.259,50$ \\
\hline
\end{tabular}

Fonte: Planilha de Preços referenciais de Terras e Imóveis Rurais do Tocantins SR-26. INCRA, 2007.

\footnotetext{
${ }^{9}$ Tentou-se buscar dados mais atuais referente ao preço de terras nas microrregiões do Tocantins. Infelizmente tais informações não foram encontradas

10 De acordo com o INCRA, o módulo fiscal é a unidade de medida expressa em hectares, fixada para cada município, considerando os seguintes fatores: tipo de exploração predominante no município; renda obtida com a exploração predominante; outras explorações existentes no município que, embora não predominantes, sejam significativas em função da renda da área utilizada e conceito de propriedade familiar. Os municípios do Tocantins adotam a medida de 80ha como módulo fiscal, exceto Araguaçu e Sandolândia onde a medida é 70ha.
} 


\section{ANÁLISE DO PREÇO DE TERRAS AGRÍCOLAS NO TOCANTINS: DECIFRANDO OS CAMINHOS DO AGRONEGÓCIO}

As cidades do Bico do Papagaio foram majoritariamente criadas nos anos 1980, influenciada pelos programas de desenvolvimento para Amazônia, e pelo corredor logístico Carajás. De acordo com o Mapa de Potencial do Uso da Terra (SEAGRO, 2012), tanto a floresta equatorial quanto os cerrados desta região permitem um uso intensivo da terra e, por conseguinte o avanço da fronteira agrícola. Neste sentido, Tocantinópolis, localizada a leste, próximo aos estados do Maranhão e Piauí é um dos principais pontos de escoamento da soja em direção ao Porto de Itaqui, localizado no município de São Luís - MA.

Araguaína é uma tradicional região da pecuária extensiva. De acordo com o Mapa de Potencial do Uso da Terra (SEAGRO, 2012), apresenta áreas potenciais para cultivos de ciclo curto e longo e pecuária intensiva, e apresenta terras valorizadas. Esta região possui uma boa rede de infraestruturas para escoamento da produção, e sitia dois pátios da Ferrovia Norte-Sul já em operação Colinas e Araguaína/Babaçulândia.

A microrregião de Gurupi apresenta altos picos de valorização no período analisado entre 2000 e 2014. A região tem recebido investimentos em irrigação. As áreas de aumento do preço da terra estão localizadas na parte oriental da microrregião, próxima à BR-153.
O Jalapão, com diversas restrições ambientais, solos frágeis e péssima rede viária possui as terras mais baratas do estado, de acordo com a tabela 1.2. Essa região possui ligações rarefeitas com os principais eixos de exportação, como a ferrovia Norte-Sul e a BR153. Mateiros e Lizarda, municípios produtores de soja desta microrregião, escoam sua produção para Luís Eduardo Magalhães - BA. No entanto, nesta abrangente divisão territorial localiza-se o município de Campos Lindos, que não apresenta as tendências da microrregião.

Dianópolis tem exposto valores da terra cada vez mais altos em detrimento dos projetos de irrigação, como o Projeto Manuel Alves. Há também plantios de soja nos municípios da microrregião de Dianópolis, como Natividade, Santa Rosa do Tocantins, ambos próximos a TO010. Dianópolis e Taguatinga, assim como Mateiros, escoa sua produção para o município baiano supracitado. 


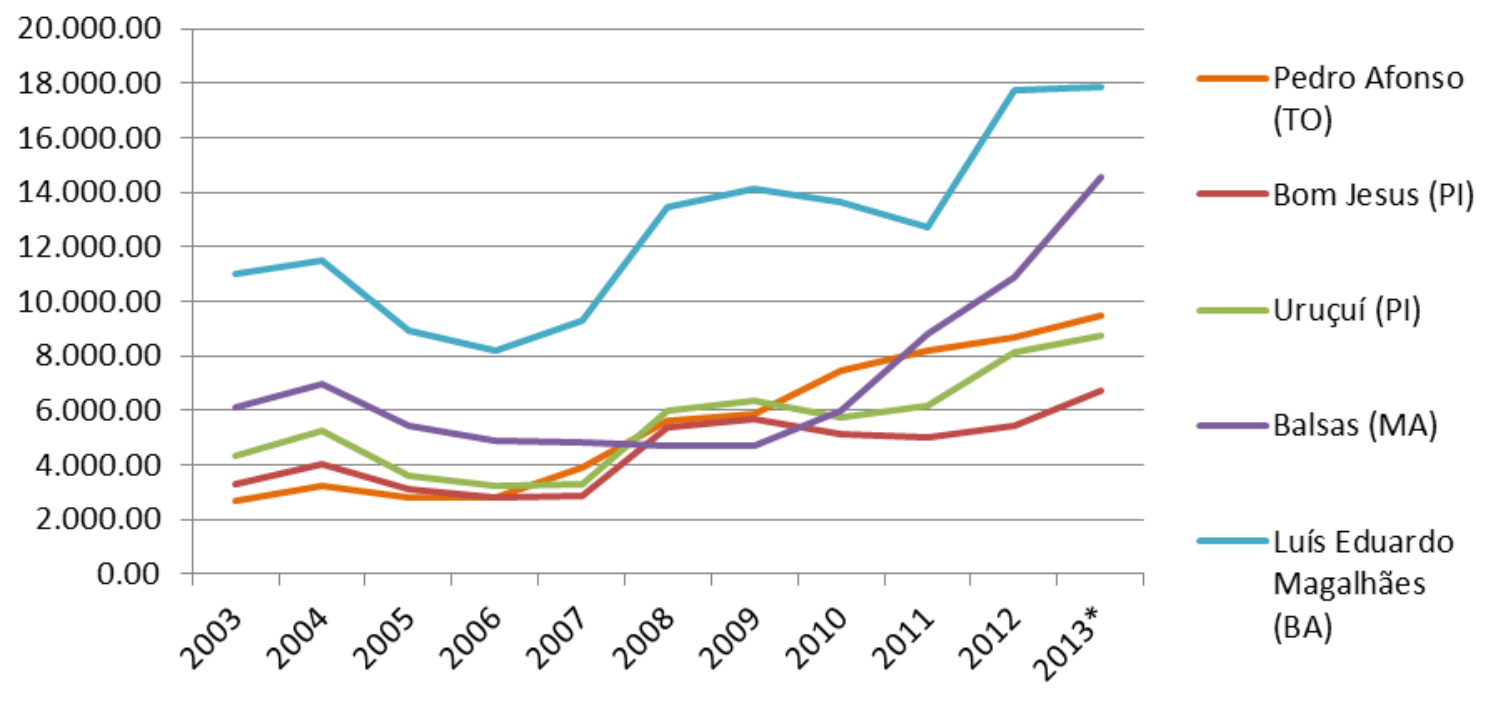

Gráfico 1.1 - Preço das terras agrícolas (R\$/ha) nos estados do corredor dos cerrados Centro-Norte (2004-2013). Fonte: FNP, 2004 a 2014. Valores reajustados pelo IGPM do período (base: abril de 2015). Organização própria.

Em 2003, as elevações do preço da terra no Tocantins são bem modestas, com exceção das áreas produtoras de soja - como a oeste da BR-153, em Palmas e Dianópolis. Em 2003, o preço da terra agrícola de soja em Campos Lindos era $\mathrm{R} \$ 2.068,00$, em Pedro Afonso, $\mathrm{R} \$ 1.340,00$ as terras de alta produtividade (aproximadamente 50 sacas por hectare) e $\mathrm{R} \$ 852,00$ as terras de baixa produtividade (aproximadamente 35 sacas por hectare) e em Porto Nacional as terras de alta produtividade eram de $\mathrm{R} \$ 893,00$. Neste mesmo ano as terras de alta produtividade em Balsas (MA) eram negociadas a $\mathrm{R} \$ 1.820,00$ o hectare; em Uruçuí (PI) R\$ 2.194,00 e no oeste baiano (nos municípios de Luís Eduardo e Novo Paraná) a R\$ 4.474,00 o hectare. No Mato Grosso (municípios de Sorriso, Lucas do Rio Verde/Nova Mutum) a terra agrícola de soja era precificada a $\mathrm{R} \$ 8.362,00$ o hectare (FNP, 2005).

O gráfico 1.1 permite afirmar que o baixo preço da terra no Tocantins em comparação aos outros estados do corredor dos cerrados CentroNorte, com exceção de Uruçuí que apresenta preços semelhantes de 2004 - 2009 e 2010 e 2012, é um fator relevante para a expansão da soja no Tocantins. As áreas de maior produtividade e com maiores infraestruturas para o circuito espacial produtivo são mais valorizadas, como Luis Eduardo Magalhães. O Maranhão, por apresentar maiores vantagens logísticas ${ }^{11}$ que o espaço tocantinense possui terras mais valorizadas (BARRAZA DE LA CRUZ, 2007).

Desde 2009, a alta do preço da soja e a expansão de investimentos em fixos de forma seletiva no território e o aumento da demanda da commoditty faz com que todas as áreas apresentadas se valorizem, como mostra o gráfico 1.2 .

\footnotetext{
11 A logística pode ser entendida como conjunto de competências matérias (infraestruturas e equipamentos relacionados ao transporte, ao armazenamento, à distribuição, à montagem de produtos industriais, aos recintos alfandegários, etc.), normativas (contratos de concessão, regimes fiscais, leis locais de tráfego, pedágios, regulações locais para carga e descarga, etc.) e operacionais (conhecimento especializado detido por prestadores de serviços ou por operadoras logísticas) (CASTILLO, 2004; VENCOVSKY e CASTILLO, 2007).
} 


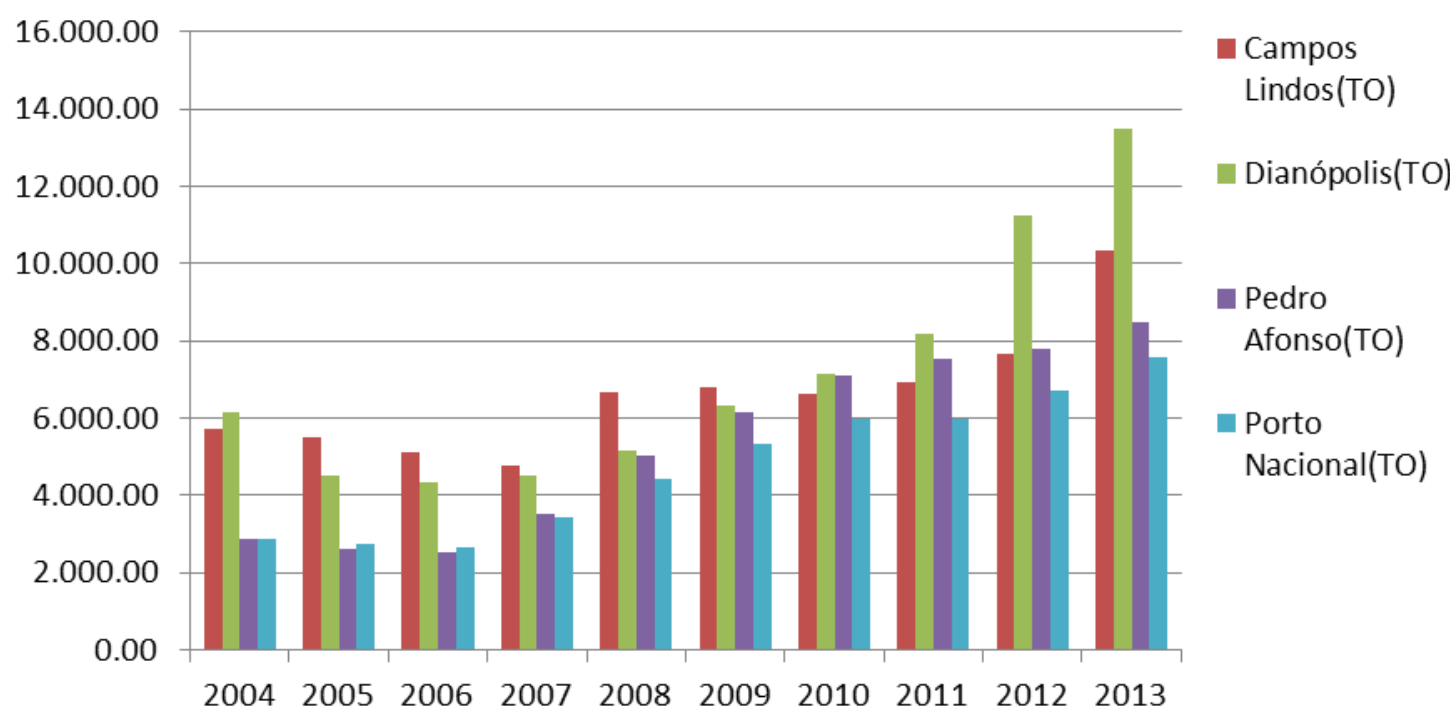

Gráfico 1.2 - Preço das terras agrícolas de soja (R\$/ha) nos municípios produtores do Tocantins (20042014). Fonte: FNP, 2004 a 2014. Valores reajustados pelo IGPM do período (base: abril de 2015). Organização própria.

Em 2006 já nota-se uma grande valorização das terras no Tocantins como aponta o gráfico 1.4: o preço das terras de alta produtividade em Campos Lindos registram $\mathrm{R} \$$ 3.429,00 - aumento de 44, 86\% referente aos valores de 2003 ; Pedro Afonso R\$ 1.634,00 6,58\% e Porto Nacional R\$ 1.703,00 - 66,06\%. Mesmo com o aumento do preço da terra, os principais municípios produtores de soja continuam atrativos. As áreas de Porto Nacional registram o maior aumento por apresentar terras que necessitam de baixo investimento em fertilizantes (FNP 2004,2005, 2006).

A correspondência entre o preço da soja e de terras continua e a estabilidade da commodity reflete no aumento constante do preço das terras a partir de 2010, como é possível observar no gráfico 1.1 e 1.2. A renda global cresce pela mera expansão do cultivo, junto ao emprego de capital e trabalho na terra.

Não há grande volume de negócios e os preços se mantêm altos de uma forma geral. A partir de 2009, as vantagens logísticas e os baixos preços relativo às terras de outros estados dos cerrados do corredor Centro-Norte aparecem como atrativos às áreas da fronteira agrícola dos cerrados Centro-Norte. As áreas de cerrado próximas a Belém-Brasília registram altas de preços, assim como a região de Pedro Afonso e Campos Lindos.

Em 2010, como registra o gráfico 1.2, as terras agrícolas de soja em Campos Lindos eram vendidas a $\mathrm{R} \$ 5.200,00$ o hectare, registrando um aumento de 12,81\% com relação ao preço de 2005. Em Pedro Afonso, o aumento foi de $148 \%$ com relação ao ano de 2005, custando $\mathrm{R} \$$ 5.467,00 o hectare. Ambos municípios estão na região do estado com maior aptidão agrícola para o plantio de soja. Porto Nacional também registrou grande aumento no período - 103\%, com terra sendo negociadas a $\mathrm{R} \$ 4.667,00$ o hectare. A partir deste ano, as terras mais caras do Tocantins passam a ser as terras agrícolas de várzea sistematizada, onde estão localizados os municípios de Lagoa da Confusão e Formoso do Araguaia, registrando em 2013 R\$ 10.700,00. Dianópolis, importante município produtor também apresenta altos valores neste ano - R\$ 13.500,00. Campos Lindos, em 2013, apresentou terras agrícolas de soja para a venda a $\mathrm{R} \$$ 10.333,00 (aumento de 65\% em relação a 2010); Pedro Afonso R\$ 8.500,00 (aumento de 29,14\% em relação ao período) e Porto Nacional $\mathrm{R} \$ 7.567,00$ (34,67\%) (FNP, 2014). 


\section{ANÁLISE DO PREÇO DE TERRAS AGRÍCOLAS NO TOCANTINS: DECIFRANDO OS CAMINHOS DO AGRONEGÓCIO}

\section{CONSIDERAÇÕES FINAIS}

Sobre a análise da evolução da agricultura na sociedade capitalista, Kautsky (1986) aponta dois pilares: "a propriedade privada com referência à terra e o caráter mercantil dos produtos agrícolas" (p.57). Harvey (2013, p. 334), sobre os mercados de terras afirma que:

a circulação "adequada" do capital mediante o uso da terra e, por isso, todo o processo de moldagem de uma organização espacial "apropriada" das atividades (repleta de contradições) estão ajustados ao funcionamento dos mercados fundiários, que por sua vez se baseiam na capacidade de se apropriar da renda.

Os municípios citados se destacam pela produção de soja e registram as maiores variações positivas de preço da terra absolutas e percentuais do Tocantins. Além disso, observa-se que tais municípios estão espraiados no estado, levando a corroborar com a ideia de que o avanço da produção da soja ocorre em pontos seletivos conectados a uma rede logística como descrito por Castillo (2004).

Do ponto de vista geográfico, a expansão do mercado de terras expressa o crescimento agrícola em área, a concentração fundiária, a transformação das relações de produção, o êxodo rural, a modernização da base técnicoprodutiva, a implantação da rede de fixos (armazéns, indústrias, latifúndios, centros de pesquisa, bancos, cidades, empresas, distribuidoras, portos, etc) e de fluxos de informação.

A paisagem monocromática dos plantios da soja avança abruptamente, em espacial nas áreas de influência da TO-010, da Ferrovia NorteSul e da BR-153, tornando essa commodity altamente representativa na pauta exportadora do estado.

As mudanças da relação com a terra transformam-se, modificando as "terras devolutas" do Estado em grandes propriedades privadas. No que tange as questões sobre a propriedade privada da terra, os processos de grilagem bem como o mercado de terras (e, por conseguinte, a especulação) também se faz presente. Com a expansão de um sistema viário e projetos de desenvolvimento o Estado auxilia a entrada do capital nacional e estrangeiro no território tocantinense. Com terras baratas e políticas de incentivo à agricultura moderna para adentrar os cerrados e a Amazônia tocantinense, o agronegócio torna-se o pilar de desenvolvimento.

O processo de expansão territorial do capitalismo possibilita, segundo esta interpretação, não só a conquista de novos territórios, mas também implica a imposição violenta das normas e da materialidade à região. O sentido é desde logo a acumulação de capital, que pode vir, mas não necessariamente, a criar as condições para que a personificação da acumulação do capital, o capitalista, possa vir a prescindir da violência, o que muda a forma institucional da imposição da territorialidade.

O Estado media a criação de formas adequadas no cerrado brasileiro para a expansão e consolidação do circuito espacial produtivo da soja de forma a inserir aqueles que dominam a agricultura científica da região do Tocantins no mercado global, aumentando a instabilidade espacial em função da turbulência do mercado mundial, exigindo contínuas readaptações das técnicas envolvidas, das empresas e das instituições.

\section{REFERÊNCIAS BIBLIOGRÁFICAS}

ALVES, V. E. Mobilização e Modernização nos Cerrados Piauienses: Formação Territorial do Império do Agronegócio. Tese (Doutorado). Faculdade de Filosofia e Ciências Humanas. Universidade de São Paulo, 2006.

ARROYO, M. M. Território nacional e mercado externo: uma leitura do Brasil na virada do século $X X$. Tese de doutorado, Departamento de Geografia (DG/FFLCH/USP), São Paulo, 2001.

BARRAZA DE LA CRUZ, B. C. Contribuição para a análise da competitividade da soja em grãos: uma aplicação do modelo de equilíbrio espacial ao estado de Tocantins. Tese de Doutorado Departamento de Engenharia Industrial, 


\section{ANÁLISE DO PREÇO DE TERRAS AGRÍCOLAS NO TOCANTINS: DECIFRANDO OS CAMINHOS DO AGRONEGÓCIO}

Pontifícia Universidade Católica do Rio de Janeiro, Rio de Janeiro: 2007.

CASTILHO, A. L. Partido da terra: como os políticos conquistaram o território. São Paulo, Editora Contexto, 2012.

CASTILLO, R. Agricultura globalizada e logística nos cerrados brasileiros. In: Circulação, transportes e logística: diferentes perspectivas. Outras Expressões. São Paulo, 2011.

CASTILLO, R. A. ; FREDERICO, S. Espaço geográfico, produção e movimento: uma reflexão sobre o conceito de circuito espacial produtivo. Sociedade \& natureza (UFU. Online), v. 22, p. 461-474, 2011.

CONAB, Companhia Nacional de Abastecimento. Acompanhamento da safra brasileira de grãos, v. 1 - Safra 2013/14, n. 3 - Terceiro Levantamento, Brasília, p. 1-72, dez. 2013.

ELIAS, D. Ensaios sobre os espaços agrícolas de exclusão. Revista NERA Presidente Prudente. Ano 9, no 8 , jan/jun, p-29-51, 2006.

FNP, AGRIANUAL. Anuário da agricultura brasileira. São Paulo: FNP Consultoria e Comércio, 2000 -2014.

HARVEY, D. Os limites do capital. São Paulo: Editora Boitempo, 2013.

HARVEY, D. O enigma do capital: e as crises do capitalismo. São Paulo: Boitempo, 2011.

GOTTMAN, J. A evolução do conceito de território. Boletim Campineiro de Geografia v.2, n3. Campinas, 2012.

KAUTSKY, K. A questão agrária. São Paulo: Nova Cultural, 1986.

LIMA, D. A. A expansão da soja na fronteira agrícola moderna e as transformações do espaço agrário tocantinense. Dissertação (Mestrado). Instituto de Geociências. Universidade Estadual de Campinas, 2014.

LOCATEL, C. CHAPARRO, J. Panorama de la agricultura informatizada en Brasil. Scripta Nova. Revista electrónica de geografía y ciencias sociales. Barcelona: Universidad de Barcelona, 1 de agosto de 2004, vol. VIII, núm. 170 (17). <http://www.ub.es/geocrit/sn/sn-170-17.htm> Acessado em 12/02/2014.

MARTINS, J. S. O tempo da fronteira. Retorno à controvérsia sobre o tempo histórico da frente de expansão e da frente pioneira. Tempo Social; Rev. Sociol. USP, S. Paulo, 8(1): 25-70, 1996.

MARTINS, J. Expropriação e violência: a questão política no campo. Petrópolis. Hucitec, 1994.

MARX, K. Formações econômicas pré-capitalistas. 5a edição. São Paulo. Paz e Terra, 1986.

MARX, K. O Capital Livro III. São Paulo: Nova Cultural, 1985.

MARX, K. Grundrisse: Manuscritos econômicos de 1857-1858: Esboços da crítica da economia política. Boitempo Editorial, 2011.

MORAES, Antonio C. R. Território e História no Brasil. São Paulo, Hucitec. 2002.

OLIVEIRA, A. U. Modo Capitalista de Produção, Agricultura e Reforma Agrária. 1a.. ed. São Paulo: FFLCU/LABUR EDIÇÕES, 2007.

OLIVEIRA, A. U. A longa marcha do campesinato brasileiro: movimentos sociais, conflitos e reforma agrária. Estudos Avançados no15 (43), 2001.

OLIVEIRA, A. U. A Agricultura Brasileira: transformações recentes. In: ROSS, J. (org.). Geografia do Brasil. 2a. Edição. São Paulo: Edusp, 1998.

OLIVEIRA, F. Elegia para uma re(li)gião. Rio de Janeiro: Paz e Terra, 1977.

RAFFESTIN, C. Por uma geografia do poder. São Paulo: Khedir Ed., 2011.

RICARDO, D. Princípios de Economia Política e Tributação. São Paulo, Nova Cultural, 1988.

SANTOS, M.; SILVEIRA, M.L. O Brasil: território e sociedade no início do século XXI. Rio de Janeiro: Record, 2001.

SILVA, C. A. F. A Fronteira Agrícola Capitalista da Soja na Amazônia. Revista Sociedade Brasileira de Geografia, 2006. s/p. Disponível em http://www.socbrasileiradegeografia.com.br/revi sta_sbg/carlos\%20a\%20f\%20silva.html Acessado dia 01/11/2013.

SILVA, C. A. F. Corporação e agronegócio da soja na Amazônia. Acta Geográfica (UFRR), v. 3, p. 2940, 2008.

SILVA, L, O. Terras devolutas e latifúndio: efeitos da lei de 1850. 2a Ed. Campinas. Editora da UNICAMP, 2008. 
LIMA,D.A. e NOBREGA,M.L.C.

ANÁLISE DO PREÇO DE TERRAS AGRÍCOLAS NO TOCANTINS: DECIFRANDO OS CAMINHOS DO AGRONEGÓCIO

TOCANTINS, Secretaria da Agricultura, Pecuária e Desenvolvimento Agrário. Tocantins: Vantagens Produtivas, Potencial de Produção. Palmas, TO. 2012.
TOCANTINS, Governo Estadual. Mapas do Tocantins. Secretaria de Agricultura, da Pecuária e Desenvolvimento Agrário. 2011 